УДК 553.981:550.41

\title{
ПЕРСПЕКТИВНАЯ ТЕХНОЛОГИЯ ДЛЯ УВЕЛИЧЕНИЯ НЕФТЕОТДАЧИ НА МЕСТОРОЖДЕНИЯХ С РАЗНОЙ ПРОНИЦАЕМОСТЬЮ ПЛАСТОВ
}

\author{
Манжай Владимир Николаевич1', \\ mang@ipc.tsc.ru \\ Ульянюк Максим Павлович2, \\ mega.ulyanyuk@mail.ru \\ Рождественский Евгений Александрович1, \\ rea876@ipc.tsc.ru \\ 1 Институт химии нефти СО РАН, \\ Россия, 634055, г. Томск, пр. Академический, 4. \\ 2 Национальный исследовательский Томский политехнический университет, \\ Россия, 634050, г. Томск, пр. Ленина, 30.
}

\begin{abstract}
Актуальность работы. Месторождения часто имеют сложную неоднородную структуру с трудно извлекаемыми запасами, разработка которых осложнена ещё и тем, что различные пропластки имеют разную проницаемость. В результате использования технологии заводнения, наиболее распространенного метода повышения нефтеотдачи, месторождение достаточно быстро становится неэфффективным, так как вода после начальной стадии нефртевытеснения начинает фрильтроваться к добывающим скважинам по уже промытым высокопроницаемым каналам. Решением данной проблемы является применение блокирующих реагентов из химических композиций, закрывающих промытые каналы и вынуждающих воду вытеснять нефть из ранее незадействованных (низкопроницаемых) зон.

Цель работы: сравнительный анализ эфффективности действия композиций на основе карбамида и уротропина в качестве блокирующих экранов для высокопроницаемых зон нефтеносного пласта, предварительно промытых водой.

Методы: моделирование процесса несттевытеснения на установке SAP-700 с двумя параллельно работающими колонками; газовый метод определения проницаемости породы.

Результаты. В лабораторных условиях на установке SAP-700 с колонками насыпного типа была экспериментально подтверждена эфффективность применения композиций на основе карбамида и уротропина в качестве основных компонентов для формирования блокирующих экранов с целью повышения коэффрициента извлечения нефти. Так, по первому эксперименту с применением композиции, содержащей в своем составе карбамид, общий коэфффициент извлечения нефти составил 0,4, из которых величина 0,16 является добавочной. Во втором же эксперименте общий коэфффициент извлечения нефрти составил 0,38, при этом 0,24 добавочные. Данные технологии для месторождений с разной проницаемостью пластов позволяют значительно увеличить степень выработки запасов по сравнению с обычным заводнением.
\end{abstract}

\section{Ключевые слова:}

Нефртеотдача, коэффиииент извлечения нефти, карбамид, уротропин, хлорид алюминия, вязкость.

\section{Введение}

Месторождения нефти представляют собой сложную комплексную структуру, и их разработка является достаточно сложной задачей. Это подтверждает и тот факт, что после применения первичных методов повышения нефтеотдачи, например, при заводнении, коэффициент извлечения нефти (КИН) редко превышает отметку 0,50 и в основном находится в пределах $0,25 \ldots 0,45$. Углеводородные ресурсы, которые остаются в недрах, в среднем составляют 55-75 \% от начальных геологических запасов. Такие показатели на сегодняшний день считаются неприемлемыми, поэтому на месторождениях практически повсеместно применяют различные методы повышения нефтеотдачи, в частности физико-химические методы [1-4].

Большая часть месторождений, расположенных внутри границ Российской Федерации, к настоящему моменту находится на поздних стадиях разработки, и извлекаемая нефть характеризуется значительной обводненностью, причинами которой являются как выработка запасов, так зачастую и высокая неоднородность геологического разреза по проницаемости [5-8]. Следствием этой неоднородности, а также процесса образования техногенной трещиноватости является возникновение высокопроницаемых каналов, по которым происходит фильтрация жидкости, результатом которой становится преждевременное обводнение добываемого флюида, также данные процессы негативно сказываются на значении коэффициента охвата месторождения [9, 10].

Одним из наиболее действенных методов повышения нефтеотдачи месторождений с разной проницаемостью пластов является закачка многокомпонентных композиций различных реагентов в виде маловязких водных растворов $\left(\eta_{\text {флюид }}=1-10 \mathrm{мПа \cdot c),} \mathrm{ко-}\right.$ торые под действием давления внешнего нагнетания легко входят в уже обводненные каналы. С течением времени под действием повышенной температуры пласта в нем протекают химические реакции с образованием новых соединений высокой вязкости и с практически нетекучей консистенцией $\left(\eta \geq 1 \cdot 10^{3}\right.$ мПа $\left.c\right)$. В peзультате промытые высокопроницаемые пропластки блокируются возникшей пастообразной системой, и дальнейшая закачка вытесняющего флюида (воды) приводит к вытеснению нефти из ранее незадействованных, т. е. низкопроницаемых, зон [11-14]. 


\section{Экспериментальная часть}

В ходе лабораторных экспериментов было проведено моделирование нефтеотдачи на месторождениях с разной проницаемостью пластов с использованием двух композиций различного состава. В качестве модели пласта использовали две металлические колонки, заполненные диспергированным керновым материалом. Предварительно подготовленные колонки помещали в стенд для определения газовой проницаемости, проводили фиксацию расхода газа и при необходимости корректировали плотность набивки кернового материала. Затем колонки помещали в экспериментальный стенд SAP-700, где проводили их последовательное насыщение водой и нефтью. Исходные данные проведенных экспериментов по нефтевытеснению на установке SAP-700 представлены в табл. 1, а сама установка - на рис. 1.

Таблица 1. Исходные данные для проведения экспериментов на установке SAP-700

Table 1. Initial data for making experiments on the SAP-700 installation

\begin{tabular}{|c|c|c|c|c|c|c|c|c|}
\hline \multicolumn{9}{|c|}{$\begin{array}{c}\text { Композиция А (8 \% карбамида, } 4 \text { \% хлорида алюминия) } \\
\text { Composition A (8 \% urea, } 4 \text { \% aluminum chloride) }\end{array}$} \\
\hline \multirow[b]{2}{*}{$\begin{array}{l}\text { Номер колонки } \\
\text { Column number }\end{array}$} & \multicolumn{5}{|c|}{ Macca, г/Mass, g } & \multirow[b]{2}{*}{$\begin{array}{c}\text { Объем пор, } \mathrm{cm}^{3} \\
\text { Pore volume, } \\
\mathrm{cm}^{3}\end{array}$} & \multirow[b]{2}{*}{$\begin{array}{l}\text { Объем нефти, } \\
\mathrm{cm}^{3} \\
\text { Oil volume, } \mathrm{cm}^{3}\end{array}$} & \multirow[b]{2}{*}{$\begin{array}{l}\text { Проницаемость } \\
\text { Permeability, D }\end{array}$} \\
\hline & $\begin{array}{l}\text { пустая } \\
\text { empty }\end{array}$ & $\begin{array}{l}\text { с керном } \\
\text { full of core }\end{array}$ & $\begin{array}{l}\text { керн } \\
\text { core }\end{array}$ & $\begin{array}{c}\text { заполненная } \\
\text { водой } \\
\text { with water } \\
\end{array}$ & $\begin{array}{c}\text { заполненная } \\
\text { нефтью } \\
\text { with oil } \\
\end{array}$ & & & \\
\hline 1 & 1190,5 & 1307,0 & 116,5 & 1331,3 & 1331,0 & 24,3 & 18,2 & 0,17 \\
\hline 2 & 1188,2 & 1298,8 & 110,6 & 1326,6 & 1328,6 & 27,8 & 23,1 & 0,62 \\
\hline \multicolumn{9}{|c|}{$\begin{array}{c}\text { Композиция Б (8 \% уротропина, } 4 \text { \% хлорида алюминия) } \\
\text { Composition В (8 \% urotropin, } 4 \text { \% aluminum chloride) }\end{array}$} \\
\hline \multirow[b]{2}{*}{$\begin{array}{l}\text { Номер колонки } \\
\text { Column number }\end{array}$} & \multicolumn{5}{|c|}{ Macca, г/Mass, $g$} & \multirow[b]{2}{*}{$\begin{array}{c}\text { Объем пор, } \mathrm{cm}^{3} \\
\text { Pore volume, } \\
\mathrm{cm}^{3}\end{array}$} & \multirow[b]{2}{*}{$\begin{array}{l}\text { Объем нефти, } \\
\mathrm{cm}^{3} \\
\text { Oil volume, } \mathrm{cm}^{3}\end{array}$} & \multirow[b]{2}{*}{$\begin{array}{l}\text { Проницаемость } \\
\text { Permeability, D }\end{array}$} \\
\hline & $\begin{array}{l}\text { пустая } \\
\text { empty }\end{array}$ & $\begin{array}{l}\text { с керном } \\
\text { full of core }\end{array}$ & $\begin{array}{c}\text { керн } \\
\text { core }\end{array}$ & $\begin{array}{c}\text { заполненная } \\
\text { водой } \\
\text { with water } \\
\end{array}$ & $\begin{array}{c}\text { заполненная } \\
\text { нефтью } \\
\text { with oil } \\
\end{array}$ & & & \\
\hline 1 & 1159,0 & 1275,3 & 116,3 & 1300,8 & 1301,2 & 25,5 & 18,9 & 0,17 \\
\hline 2 & 1144,2 & 1252,6 & 108,4 & 1280,0 & 1280,2 & 27,4 & 22,7 & 0,59 \\
\hline
\end{tabular}

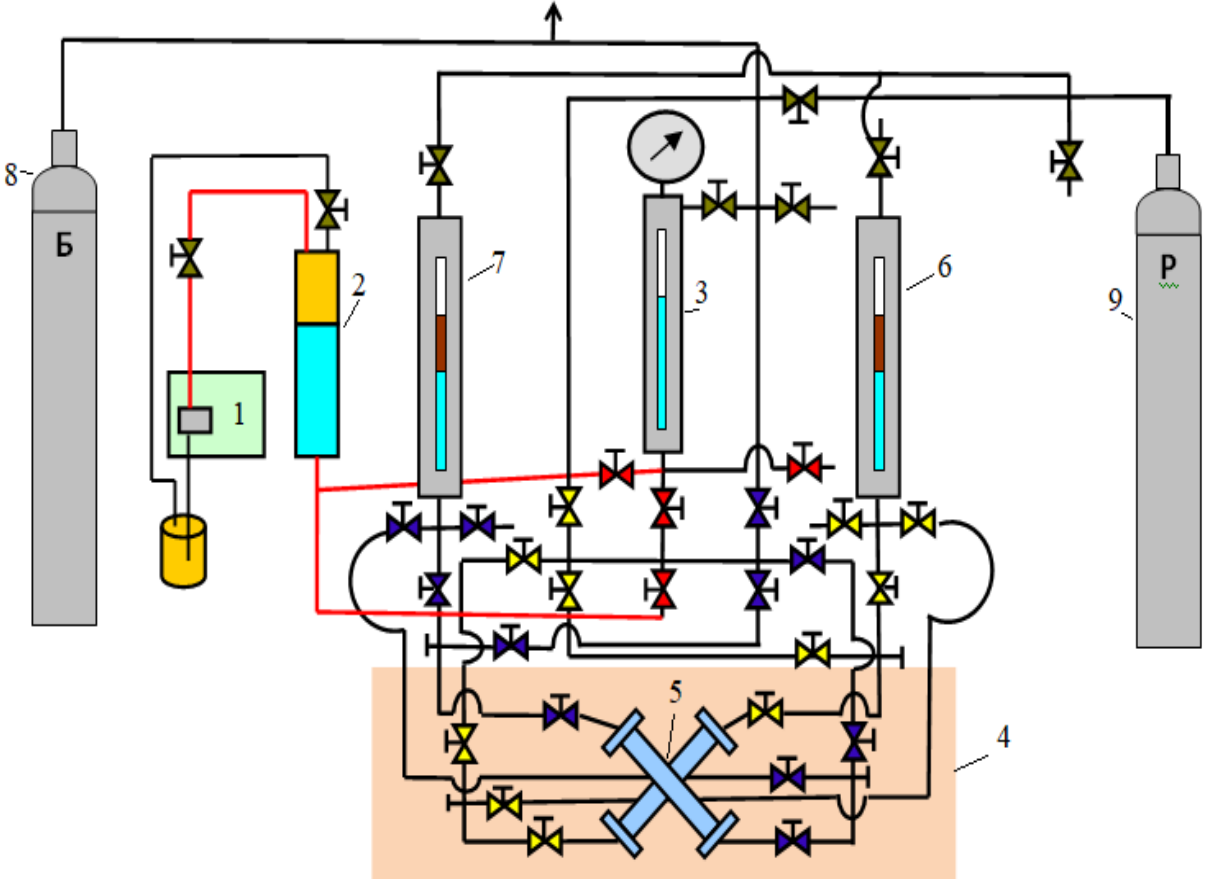

Рис. 1. Схема установки для изучения фильтрации жидкостей при моделировании пластовых условий и определения коэффициента вытеснения нефти: 1 - поршневой насос; 2 - контейнер с композицией; 3 - демпфер -мерник; 4 - термошкаф; 5 - колонки с керновым материалом; 6, 7 -мерники для нефти и воды; 8, 9 - баллоны с азотом для моделирования пластового давления в колонках

Fig. 1. Scheme of the setup for determining oil recovery factor and studying the fluid filtration during simulation of reservoir conditions: 1 - the piston pump; 2 - the tank with composition; 3 - the damper - measuring device; 4 - the thermostat; 5 - the columns with a core material; 6, 7 - the measuring points for oil and water; 8, 9 - the cylinders with nitrogen to simulate reservoir pressure in columns

До начала эксперимента две колонки наполнили диспергированным керновым материалом известной проницаемости, которую измерили газовым методом, и затем пропитали их пластовой водой. В опытах с обеими композициями проницаемость низко- и высо- копроницаемой колонок отличалась примерно в 3 раза (табл. 1). Динамическая вязкость нефти, использованной в экспериментах, равна $\eta_{\text {нефть }}=12$ мПа.с. Плотность нефти при температуре 293 К составляла $\rho_{\text {нефть }}=0,854 \mathrm{r} / \mathrm{cm}^{3}$, а вязкость $\left(\eta_{\text {пл.вода }}\right)$ и плотность 


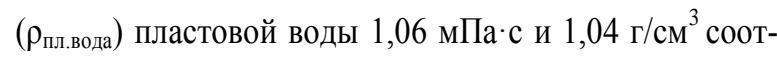
ветственно. Увеличение массы колонок после введения в них измеренного количества нефти (табл. 1) вместо частично удаленной пластовой воды вызвано тем, что при первичном насыщении их водой не все поры кернового материала были заполнены жидкостью. В колонках оставался воздух, который и искажал массу в меньшую сторону по сравнению с массой колонок, которые затем были полностью заполнены нефтью. Предполагается, что во время насыщения колонок нефтью частично оставшаяся в них вода была продавлена в ранее незанятые пустоты.

Во время проведения эксперимента на лабораторном стенде (рис. 1) вода поршневым насосом (1) через промежуточные ёмкости (2 и 3) с вытесняющим флюидом или композицией нагнеталась в две параллельные колонки (5) с керновым материалом, насыщенные известным количеством нефти. Колонки, помещенные в термошкаф (4) при температуре 363 К, находились под повышенным давлением азота (8), моделирующим пластовое давление. Вытесненная нефть и вода накапливались в мерниках (6 и 7) в контролируемых во времени и измеряемых объёмах $\left(\mathrm{V}_{\text {Пор }}\right)$. Результаты экспериментов использовали в последующих расчетах и при построении графических иллюстраций.

Фильтрацию воды и сбор вытесняемой продукции продолжали до момента прорыва воды через высокопроницаемую колонку, которая происходила примерно через 100 минут (рис. 2). Затем из емкости (2) также при помощи насоса (1) проводили закачку оторочки композиций с карбамидом (А) или с уротропином (Б), равную четверти суммарного порового объёма двух колонок $\left(0,25 \cdot \mathrm{V}_{\text {Пор. }}\right)$. После введения композиций в колонки в первом (А) или во втором (Б) экспериментах установку оставляли в покое на 24 часа при температуре 363 К в термостате (4). За это время компоненты маловязких композиций успевают прореагировать с образованием высоковязкого геля и заблокировать каналы (капилляры), уже промытые от нефти. Далее возобновили фильтрацию воды через колонки до максимально возможного вытеснения нефти.

Состав первой композиции (А) для получения высоковязкого продукта химической реакции (геля) представляет собой маловязкий водный раствор ( $\sim 1,4$ мПа·c), содержащий 8 \% карбамида и 4 \% хлорида алюминия. Исходный раствор обладает ярко выраженными кислотными свойствами ( $\mathrm{pH}$ 2-3), которые являются следствием гидролиза соли $\left(\mathrm{AlCl}_{3}\right)$ сильной кислоты и слабого основания.

Технологическая и физико-химическая суть процесса образования продукта высоковязкой консистенции из исходной маловязкой композиции заключается в том, что при прокачке оторочки трехкомпонентной композиции по стволу скважины её температура повышается незначительно. Но при достижении целевого пласта, температура которого выше 363 К, в растворе начинает протекать химическая реакция со скоростью, нарастающей по мере прогрева и увеличения температуры исходной композиции. Известно, что растворенный в воде карбамид только при нагревании разлагается с выделением аммиака $\left(\mathrm{NH}_{3}\right)$ и диоксида углерода $\left(\mathrm{CO}_{2}\right)$. Аммиак растворяется в воде и с течением времени способствует постепенному повышению $\mathrm{pH}$ среды от кислого до щелочного состояния (рН>7), а диоксид углерода снижает вязкость нефти вследствие его абсорбции в углеводородной фазе [15]. Когда система достигает значений рН примерно равной 4-5, в обводненных капиллярах и трещинах, пропитанных композицией, происходит практически мгновенное и объёмное образование пастообразного геля гидроксида алюминия $\mathrm{Al}(\mathrm{OH})_{3}$, который блокирует промытый высокопроницаемый пропласток. Эффективность данной композиции как блокирующего агента подтверждается и реологическими исследованиями, проведенными на ротационном вискозиметре [16-20], по результатам которых было выявлено, что через 24 часа после начала прогрева вязкость системы увеличивается примерно на три порядка.

$$
3\left(\mathrm{NH}_{2}\right)_{2} \mathrm{CO}+2 \mathrm{AlCl}_{3}+9 \mathrm{H}_{2} \mathrm{O} \rightarrow 3 \mathrm{CO}_{2} \uparrow+6 \mathrm{NH}_{4} \mathrm{Cl}+2 \mathrm{Al}(\mathrm{OH})_{3} \downarrow
$$

Состав второй композиции (Б) представляет собой также маловязкий водный раствор ( $\sim 1,4$ мПа॰c), содержащий 4 \% хлорида алюминия, но вместо карбамида в ней присутствует $8 \%$ уротропина $\left(\mathrm{C}_{6} \mathrm{H}_{12} \mathrm{~N}_{4}\right)$. Процесс изменения $\mathrm{pH}$ раствора от кислого к щелочному состоянию протекает аналогично. Уротропин разлагается с образованием формальдегида $\left(\mathrm{CH}_{2} \mathrm{O}\right)$ и воды, а также с выделением аммиака, растворение которого в воде ведет к её подщелачиванию. Хлорид алюминия в щелочной среде подвергается гидролизу с образованием гелеобразного осадка $\mathrm{Al}(\mathrm{OH})_{3}$. Основное отличие данного процесса от описанного ранее заключается в более низкой температуре реакции $(313 \mathrm{~K})$, а также в отсутствии углекислого газа в числе образующихся продуктов.

$3 \mathrm{C}_{6} \mathrm{H}_{12} \mathrm{~N}_{4}+4 \mathrm{AlCl}_{3}+30 \mathrm{H}_{2} \mathrm{O} \rightarrow 18 \mathrm{CH}_{2} \mathrm{O}+12 \mathrm{NH}_{4} \mathrm{Cl}+4 \mathrm{Al}(\mathrm{OH})_{3} \downarrow$

\section{Анализ результатов экспериментов}

По данным экспериментов были построены графические зависимости накопления вытесненной нефти от времени (рис. 2), а также зависимость изменения давления в процессе фильтрации (рис. 3). Из представленных зависимостей отчетливо видно (рис. 2), что вплоть до введения композиций в установку вытеснение нефти наблюдается практически только из высокопроницаемой колонки, что значительно снижает КИН.

Анализируя графики изменения давления в установке (рис. 1) для обоих экспериментов с композициями (А и Б), можно выделить два характерных пика (рис. 3). Появление первого пика в обоих экспериментах обусловлено преодолением сопротивления нефти, которая на начальном этапе процесса вытеснения занимает в порах керна бо́льшую часть длины высокпроницацаемой колонки (I). Из низкопроницаемой колонки (II) фильтрация при этом практически отсутствует. По мере вытеснения нефти, имеющей более высокую вязкость по сравнению с водой, бо́льшая часть высокопроницаемой колонки освобождается от нефти и заполняется маловязкой водой, 
поэтому общее давление в установке уменьшается и выходит на некоторое плато, появление которого на рис. 3 свидетельствует о прорыве воды через высокопроницаемую колонку. После нагнетания в промытую водой высокопроницаемую колонку маловязких композиций А или Б и формирования в ней при повышенной температуре высоковязкого (блокирующе- го) геля гидроксида алюминия начинается фильтрация жидкости (вытесняющего флюида и нефти) уже из низкопропроницаемой колонки, что сопровождается повторным повышением давления. После вытеснения нефти из низкопропроницаемой колонки давление снова выходит на плато, но уже при больших значениях.
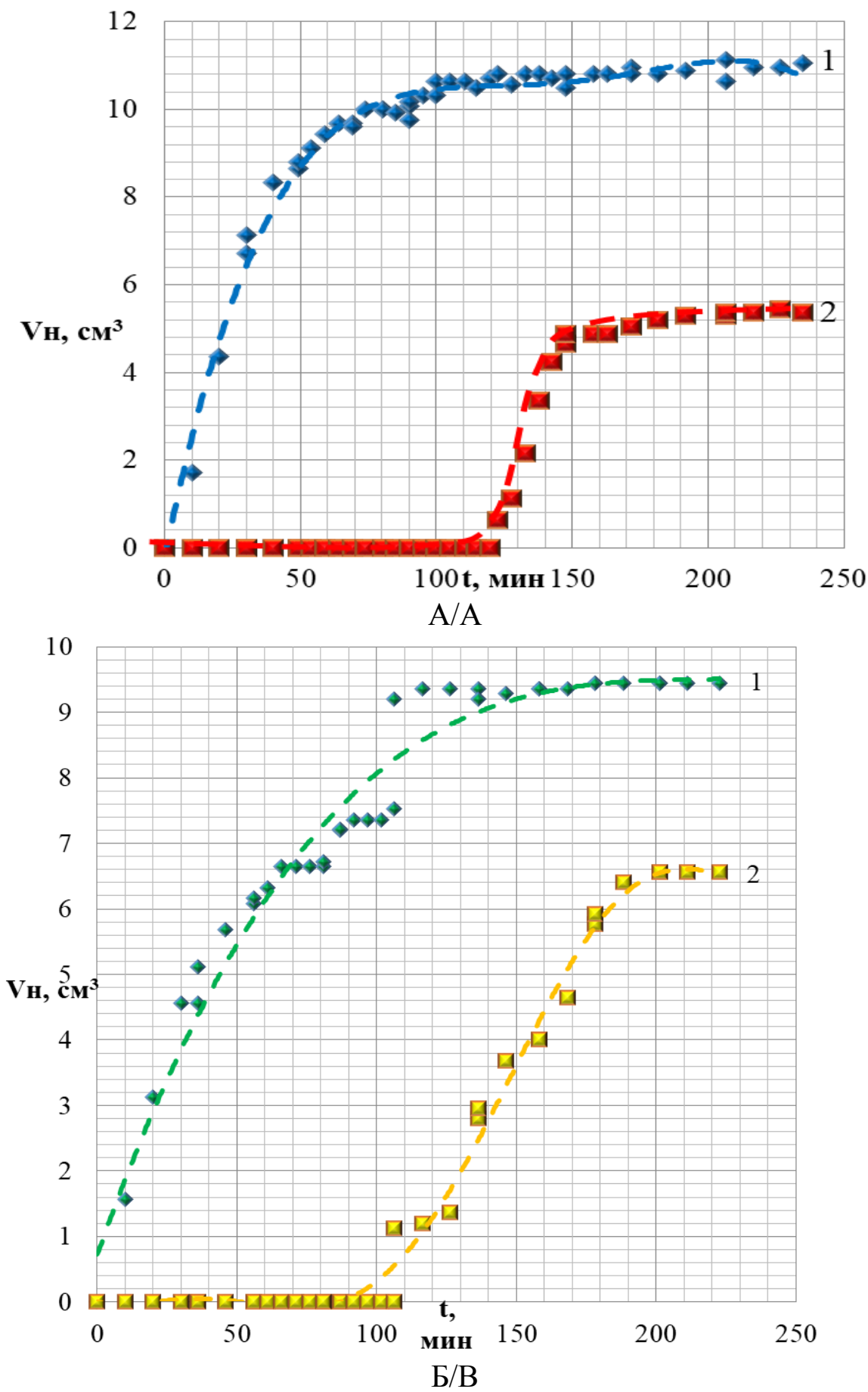

Рис. 2. Зависимости накопления вытесненной нефти от времени в экспериментах при использовании композиций на основе: А) карбамида; Б) уротропина: 1 - нефть из высокопроницаемой колонки; 2 - нефть из низкопронииаемой колонки

Fig. 2. Relationships of cumulative oil and water production on time using composition based on: A) urea; B) urotropin: 1 - oil from high-permeable sample; 2 - oil from low-permeable sample 
23

22

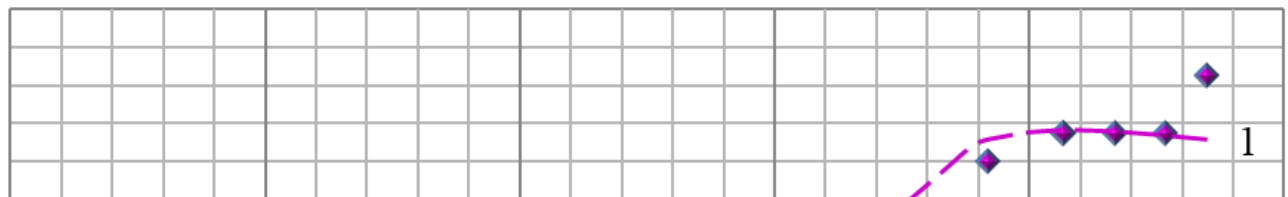

21

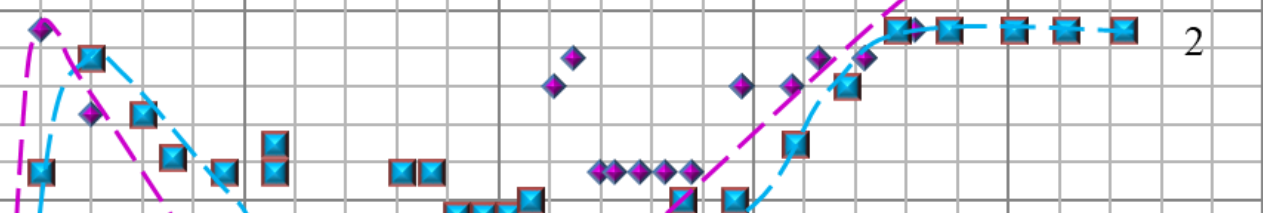

$-$

20

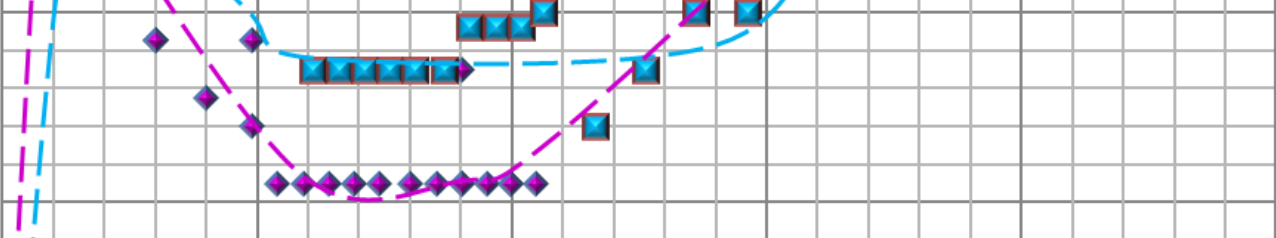

Pвх, атм

19

II

18

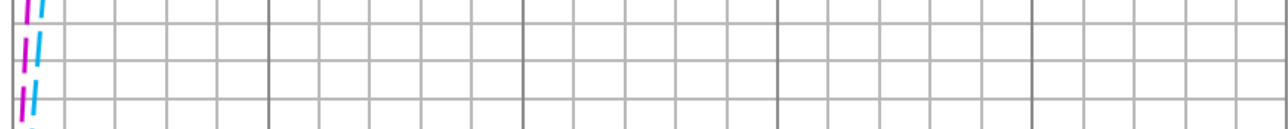

9

†1

17

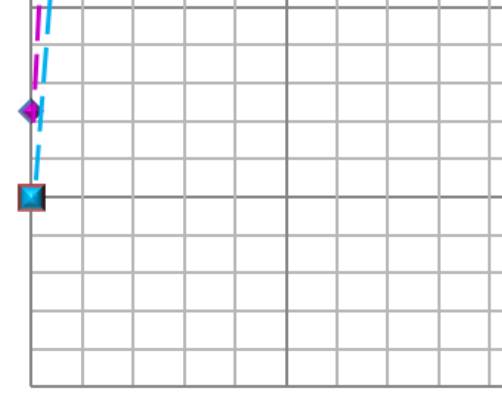

0

50

100

t, мин 150

Рис. 3. Зависимость изменения давления в установке от времени в экспериментах с разными композициями: 1 карбамидом; 2 - уротропином

Fig. 3. Dependence of the change in pressure at the entrance to the system on time in the experiment with: 1 - urea; 2 urotropin

Таблица 2. Изменение КИН до и после закачки композиичй $A$ и $B$

Table 2. Recovery factor (RF) before and after using $A$ and $B$ composition

\begin{tabular}{|c|c|c|c|}
\hline \multicolumn{2}{|c|}{$\begin{array}{c}\text { Композиция А (8 \% карбамида; } \\
4 \text { \% хлорида алюминия; } \\
88 \text { \% вода) } \\
\text { Composition A (8 \% urea; } \\
4 \% \text { aluminum chloride; } \\
88 \% \text { water) }\end{array}$} & \multicolumn{2}{|c|}{$\begin{array}{c}\text { Композиция В (8 \% уротропина; } \\
4 \text { \% хлорида алюминия; } \\
88 \% \text { вода) } \\
\text { Composition B (8 \% urotropin; } \\
4 \% \text { aluminum chloride; } \\
88 \% \text { water) }\end{array}$} \\
\hline КИН/RF & 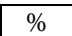 & КИН/RF & $\%$ \\
\hline $\begin{array}{l}\text { Без композиции } \\
\text { Before using compositio }\end{array}$ & 25,0 & \begin{tabular}{|l|} 
Без композиции \\
Before using compositiol
\end{tabular} & 14,0 \\
\hline $\begin{array}{l}\text { С композицией } \\
\text { After using composit }\end{array}$ & 40,0 & $\begin{array}{l}\text { С композицией } \\
\text { After using compositi }\end{array}$ & 38,0 \\
\hline бавочный/Additional & 15,0 & Добавочный/Additional & 24,0 \\
\hline
\end{tabular}

Помимо построения графических зависимостей, представленных на рис. 2, 3, также был оценен КИН до и после закачки композиций. Результаты приведены в табл. 2.

\section{СПИСОК ЛИТЕРАТУРЫ}

1. Шубин А., Шустер М. Химия и нефть. Щелочь-ПАВполимерное заводнение - эффективный метод увеличения нефтеотдачи // Приложение к журналу «Сибирская нефть». 2014. - № 2/109. - C. 17-25.

\section{Заключение}

Как видно из результатов экспериментов (табл. 2), суммарные коэффициенты извлечения нефти для каждой композиции составили $\mathrm{A}=0,40$ и $\mathrm{B}=0,38$ соответственно, при этом величины 0,15 и 0,24 являются добавочными значениями КИН, которые были получены благодаря применению композиций. Экспериментально полученные результаты позволяют сделать вывод, что ввиду значительного увеличения КИН, а также вследствие доступности и невысокой стоимости компонентов композиций их применение является обоснованным как с технологической, так и с экономической точек зрения.

Работа выполнена в рамках государственного задания ИХН СО РАН, финансируемого Министерством науки и выстего образования Российской Федеращии.

2. Миловидов К.Н., Колчанова Т.И. Мировая практика применения методов повышения нефтеотдачи // НТЖ «Нефтегазопромысловое дело». - 2002. - № 8. - С. 46-48.

3. Жданов С.А. Опыт применения методов увеличения нефтеотдачи в России // Нефтяное хозяйство. - 2008. - № 1. - С. 58-61. 
4. Алтунина Л.К., Кувшинов В.А. Увеличение нефтеотдачи пластов композициями ПАВ. - Новосибирск: Изд-во «Наука», 1995. - $198 \mathrm{c}$.

5. Федорова А.Ф., Шиц Е.Ю., Портнягин А.С. Исследование возможности применения растворов полимеров в качестве агентов вытеснения нефти на месторождениях с аномально низкими пластовыми температурами // Электронный научный журнал «Нефтегазовое дело». - 2008. - № 1. - С. 12-22.

6. Tabary R., Bazin B. Advances in chemical flooding // Improved Oil recovery (IOR) Techniques and Their Role in Boosting the Recovery Factor: IFP-OAPEC Joint Seminar. - France, 2007.

7. Levitt D.B., Pope G.A. Selection and screening of polymers for enhanced-oil recovery // SPE Symposium on Improved Oil Recovery. - Tulsa: USA, 2008. - P. 1125-1143.

8. Shandrygin A., Lutfullin A. Current status of enhanced recovery techniques in the fields of Russia // SPE Annual Technical Conference and Exhibition. - Denver, Colorado, USA, 2008. P. 1929-1946.

9. Thomas A. Polymer Flooding, Chemical Enhanced Oil Recovery (cEOR) - a practical overview / Ed. by Dr. L. Romero-Zerón. 2016. DOI: $10.5772 / 64623$.

10. EOR: Current status and opportunities / E.J. Manrique, C. Thomas, R. Ravikiran, M. Izadi, M. Lantz, J. Romero, V. Alvarado // SPE Improved Oil Recovery Symposium. - Tulsa, USA, 2010. P. 1584-1604.

11. Способ регулирования разработки нефтяного месторождения c разнопроницаемыми пластами: пат. Рос. Федерация. № 2061856; заявл. 30.06.92; опубл. 10.06.96, Бюл. № 16. - 6 с.

12. Состав для повышения нефтеотдачи пластов: пат. Рос. Федерация. № 2066743; заявл. 08.02.93; опубл. 20.09.96, Бюл. № 26. $7 \mathrm{c}$.

13. Способ регулирования разработки нефтяного месторождения: пат. Рос. Федерация. № 2467165; заявл. 11.10.10; опубл. 20.11.12, Бюл. № 32. -9 с.

\section{Информация об авторах}

Манжай В.H., доктор химических наук, старший научный сотрудник Института химии нефти СО РАН.

Ульянюк М.П., магистрант Инженерной школы природных ресурсов Национального исследовательского Томского политехнического университета.

Рождественский $\boldsymbol{E} . \boldsymbol{A}$., ведущий инженер Института химии нефти СО РАН.
14. Enhanced oil recovery techniques for heavy oil and oilsands reservoirs after steam injection (review) / Xiaohu Donga, Huiqing Liua, Zhangxin Chena, Keliu Wua, Ning Lua, Qichen Zhanga // Journ. Applied Energy. - 2019. - № 239. - P. 1190-1211.

15. Кувшинов В.А., Алтунина Л.К., Стасьева Л.А. Кинетика гелеобразования в системе соль алюминия - карбамид - вода // Физико-химические свойства растворов и дисперсий. - Новосибирск: Наука, 1992. - С. 18-24.

16. Кувшинов В.А., Манжай В.Н., Алтунина Л.К. Реологическое исследование системы соль алюминия - карбамид - вода // Физико-химические свойства растворов и дисперсий. - Новосибирск: Наука, 1992. - С. 24-30.

17. Кувшинов И.В., Алтунина Л.К., Кувшинов В.А. Комбинированная обработка скважин химическими композициями различного назначения в сочетании с термическим воздействием // Журн. СФУ. Химия. - 2019. - Т. 12. - № 4. - С. 473-482.

18. Увеличение нефтеотдачи залежей высоковязких нефтей кислотными композициями на основе поверхностно-активных веществ, координирующих растворителей и комплексных соединений / Л.К. Алтунина, В.А. Кувшинов, Л.А. Стасьева, И.В. Кувшинов // Георесуры. - 2019. - Т. 21. - № 4. - С. 103-113.

19. Pope G.A. Overview of Chemical EOR // Casper EOR Workshop. - Austin, The University of Texas, October 26th 2007. multifunctional systems based on surfactants / L.K. Altunina, V.A. Kuvshinov, L.A. Stasieva, I.V. Kuvshinov // Journ. of Physics: Conference Series. - 2020. - V. 1611. - № 1. - 012033. DOI: $10.1088 / 1742-6596 / 1611 / 1 / 012033$.

Поступила 15.07.2021 2.
20. Enhanced oil recovery for deposits of high viscosity oils using 
UDC 553.981:550.41

\title{
PROMISING TECHNOLOGY FOR ENHANCED OIL RECOVERY OF OILFIELDS WITH DIFFERENT RESERVOIR PERMEABILITY
}

\author{
Vladimir N. Manzhay', \\ mang@ipc.tsc.ru
}

\author{
Maksim P. Ulyanyuk2, \\ mega.ulyanyuk@mail.ru
}

\author{
Evgeny A. Rozhdestvensky ${ }^{1}$, \\ rea876@ipc.tsc.ru \\ 1 Institute of Petroleum Chemistry of the SB RAS, \\ 4, Academichesky avenue, Tomsk, 634055, Russia. \\ 2 National Research Tomsk Polytechnic University, \\ 30, Lenin avenue, Tomsk, 634050, Russia.
}

\begin{abstract}
Relevance. Oil deposits often have a complex heterogeneous structure with hard-to-recover reserves, the development of which is complicated by the fact that different layers have different permeability. As a result, the use of flooding, the most common method of increasing oil recovery, quickly becomes ineffective as water begins to circulate through washed, highly permeable channels. The solution to this problem is the use of blocking agents, special compositions that close these channels and force water to displace oil from previously unused zones.

The main aim of the research is the analysis of the effectiveness of compositions based on urea and urotropin as blocking agents in enhanced oil recovery process.

Research methods: simulation of oil displacement process on SAP-700 setup with two parallel columns; gas method for determining permeability of the rock.

Results. The effectiveness of the use of compositions based on urea and urotropin as blocking agents in order to increase recovery factor was experimentally confirmed in laboratory conditions. The first experiment showed that ultimate oil recovery factor was $0,4,0,16$ of which was additional The second experiment showed, that ultimate recovery factor was 0,38, 0,24 of which was additional. These technologies for oilfields with different reservoir permeability can significantly increase the degree of reserve development compared to conventional flooding.
\end{abstract}

\section{Key words:}

Enhanced oil recovery, oil recovery factor, urea, urotropin, viscosity.

The research was carried out within the State task of the OCI SB RAS, financially supported by the Ministry of Sciences and Higher Education of the Russian Federation.

\section{REFERENCES}

1. Shubin A., Shuster M. Chemistry and oil. Alkali - surfactant polymer flooding - an effective method for increasing oil recovery. Supplement to the journal Siberian Oil, 2014, no. 2/10, pp. 17-25. In Rus.

2. Milovidov K.N., Kolchanov T.I. World practice of application of methods of increase of oil recovery. Neftegazopromyslovoe delo, 2002, no. 8, pp. 45-49. In Rus.

3. Zhdanov S.A. Experience in applying methods to increase oil recovery in Russia. Oil industry, 2008, no. 1, pp. 57-61. In Rus.

4. Altunina L.K., Kuvshinov V.A. Uvelichenie nefteotdachi plastov kompozitsiyami PAV [Increase in oil recovery of reservoirs by surfactant compositions]. Novosibirsk, Nauka Publ., 1995. 198 p.

5. Fedorova A.F., Shits E.Yu., Portnyagin A.S. Investigation of the possibility of using polymer solutions as agents for displacement of oil in fields with anomalously low reservoir temperatures. Electronic Scientific Journal «Oil and Gas Business», 2008, no. 1, pp. 12-23. In Rus.

6. Tabary R., Bazin B. Advances in Chemical Flooding. IFP-OAPEC Joint Seminar. Improved Oil Recovery (IOR) Techniques and Their Role in Boosting the Recovery Factor. France, 2007.

7. Levitt D.B., Pope G.A. Selection and screening of polymers for enhanced - oil recovery. SPE Symposium on Improved Oil Recovery. Tulsa, USA, 2008. pp. 1125-1142.

8. Shandrygin A., Lutfullin A. Current status of enhanced recovery techniques in the fields of Russia. SPE Annual Technical Conference and Exhibition. Denver, Colorado, USA, 2008. pp. 1929-1946.
9. Thomas A. Polymer Flooding, Chemical Enhanced Oil Recovery (cEOR) - a practical overview. Ed. by Dr. Sc. L. Romero-Zerón. 2016. DOI: $10.5772 / 64623$

10. Manrique E.J., Thomas C., Ravikiran R., Izadi M., Lantz M., Romero J., Alvarado V. EOR: Current status and opportunities. SPE Improved Oil Recovery Symposium. Tulsa, USA, 2010. SPE130113. pp. 1584-1604.

11. Altunina L.K., Kuvshinov V.A., Stasyeva L.A., Manzhay V.N., Nazarov V.I., Bernshtein A.M., Polkovnikov V.V., Tarasov A.G. A method for regulating the development of an oil field with multi-permeable layers. Patent RF, no. 2061856, 1996.

12. Altunina L.K., Kuvshinov V.A., Stasyeva L.A. A composition for oil recovery increasing. Patent RF, no. 2066743, 1996.

13. Altunina L.K., Kuvshinov V.A., Stasyeva L.A. A method for regulating the development of an oil field. Patent RF, no. 2467165 , 2012.

14. Xiaohu Donga, Huiqing Liua, Zhangxin Chena, Keliu Wua, Ning Lua, Qichen Zhanga. Enhanced oil recovery techniques for heavy oil and oilsands reservoirs after steam injection (review). Journ. Applied Energy, 2019, no. 239, pp. 1190-1211.

15. Kuvshinov V.A., Altunina L.K., Stasyeva L.A. kinetika geleobrazovaniya $\mathrm{v}$ sicteme col aluminiya - karbamid - voda [Kinetics of gel formation in aluminate - carbamide - water system]. Fiziko-khimicheskie svoystva rastvorov $i$ dispersy [Compendium: physical and chemical properties of solutions and dispersions]. Novosibirsk, Nauka Publ., 1992. pp. 18-24. 
16. Kuvshinov V.A., Manzhay V.N., Altunina L.K. Reologicheskoe issledovanie sistemy sol aluminiy - karbamid - voda [Rheological study of the aluminum salt - urea - water system]. Fizikokhimicheskie svoystva rastvorov $i$ dispersy [Compendium: Physical and chemical properties of solutions and dispersions]. Novosibirsk, Nauka Publ., 1992. pp. 24-30.

17. Kuvshinov I.V., Altunina L.K., Kuvshinov V.A. Combined wells treatment with various chemical compositions and thermal methods. Zhurn. SFU. Khimiya, 2019, vol. 12, no. 4, pp. 473-482. In Rus.

18. Altunina L.K., Kuvshinov V.A., Stasyeva L.A., Kuvshinov I.V. Enhanced oil recovery from high-viscosity oil deposits by acid systems based on surfactants, coordining solvents and complex compounds. Georesursy, 2019, vol. 21, no. 4, pp. 103-113. In Rus. 19. Pope G.A. Overview of Chemical EOR. Casper EOR Workshop. Austin, October 26th 2007.

20. Altunina L.K., Kuvshinov V.A., Stasieva L.A., Kuvshinov I.V. Enhanced Oil Recovery for deposits of high viscosity oils using multifunctional systems based on surfactants. Journ. of Physics: Conference Series, 2020, vol. 1611, no. 1. DOI: 10.1088/1742$6596 / 1611 / 1 / 012033$

Received: 15 July 2021.

\section{Information about the authors}

Vladimir N. Manzhay, Dr. Sc., senior researcher, Institute of Petroleum Chemistry of the SB RAS.

Maksim P. Ulyanyuk, graduate student, National Research Tomsk Polytechnic University.

Evgeny A. Rozhdestvensky, leading engineer, Institute of Petroleum Chemistry of the SB RAS. 